\title{
Ram Coin Dimpling: Assessment of Modern Dimpling Methods
}

\author{
Ishimwe Irene Fidele \\ School of Aircraft Engineering, Nanchang Hangkong University, Nanchang, People's Republic of China
}

\section{Email address:}

fidish55@yahoo.fr

\section{To cite this article:}

Ishimwe Irene Fidele. Ram Coin Dimpling: Assessment of Modern Dimpling Methods. International Journal of Mechanical Engineering and Applications. Vol. 9, No. 3, 2021, pp. 42-49. doi: 10.11648/j.ijmea.20210903.11

Received: July 27, 2021; Accepted: August 6, 2021; Published: August 13, 2021

\begin{abstract}
Given the increasing necessity of improving the structural assembly methods especially in the aviation industry; a proper study by comparison of the currently used methods could reveal to be helpful in choosing the right method to achieve one's manufacturing goals. It could also incite further researches to solve the existing deficiencies in this domain or make more efficient the existing ones. With the above-mentioned motives, this paper is a close look at dimpling methods. This paper will revise the key characteristics of hot dimpling and cold dimpling by experimental results on sheet materials with different properties. Tensile test and shear test were carried out to evaluate the strength of the sheet material after each dimpling method and study diverse failures remarked while doing experiments. The dimples' status, fatigue and especially radial cracks and hole sizes, is evaluated. We wish to achieve dimples that permit the rivets to sit flush with the surface of the surrounding material and rivet's head to fit with no defect. Due to the increasing complexities encountered in the manufacturing and assembly of air and space vehicles, missile systems and associated equipment, this research is provided to be used as an enlightenment to dimpling processes; especially ram coin dimpling. The ram coin dimpling method is divided into cold dimpling (room temperature) and hot dimpling (increased temperature). Comparing this research paper to the studies previously done, we found that hot dimpling though requiring a lot more attention proves to be more efficient on thick or brittle sheet materials, where cold dimpling would produce radial cracks.
\end{abstract}

Keywords: Ram Coin Dimpling, Countersinking, Riveting, Sheet Material, Deburring, Tensile Test

\section{Introduction}

In order to obtain high strength structural connections and smooth aerodynamic surfaces, a large number of countersunk rivets, countersunk bolts and screws are often used in modern aircraft industry. Countersinking in thin thickness sheet materials causes stress concentration which accelerates crack nucleation [1]. When these fasteners are used for thin skin and medium thickness skin connections, ram coin dimpling can, not only avoid the stress concentration caused by countersinking, but also increase the shear extrusion area and tensile area of the dimple hole. Müller [2] has worked on showing the impact that riveting has on the fatigue performance of joints. Therefore, we know that any alterations due to countersinking or dimpling will also affect the fatigue life $[3,4]$.

The local stress concentration for dimpling is lower than countersinking, and the tensile strength is higher than countersinking [5]. Consequently, countersinking is not allowed to be used when a specified product is set to be dimpled. Doing so would definitely give unwanted results. we can use dimpling on materials such as stainless steel, titanium, aluminum and magnesium. When the drawing or process document does not indicate which method to be used, the method can be selected according to the skin thickness and framework thickness. In most cases, when the thickness of skin and framework is less than $0.8 \mathrm{~mm}$, dimpling can be used; when the thickness of skin is less than $0.8 \mathrm{~mm}$ and the thickness of framework is greater than $0.8 \mathrm{~mm}$, dimpling can be used for skin and countersinking for the framework.

Table 1 from Bombardier Aerospace, structural repair manual [6] shows detailed numbers about this theory.

It's worth mentioning that rivets should not be used in thick materials or in tensile applications, as their tensile strengths 
are quite low relative to their shear strength. The longer the total grip length (the total thickness of sheets being joined), the more difficult it becomes to lock the rivet. In this way, dimpling has certain limitations on the material form. That is to say, dimples are better off carried out on thin plate products, but not for extruded products.

Table 1. Sheet material thickness relationship with Dimpling and countersinking for rivets [6].

\begin{tabular}{lllllll}
\hline \multirow{2}{*}{ GAUGE $(\mathbf{m m})$} & \multicolumn{6}{l}{ RIVET DIAMETER (INCHES) } \\
\cline { 2 - 7 } & $\mathbf{3 \backslash 3 2}$ & $\mathbf{1} \backslash \mathbf{8}$ & $\mathbf{5} \backslash \mathbf{3 2}$ & $\mathbf{3} \backslash \mathbf{1 6}$ & $\mathbf{7} \backslash \mathbf{3 2}$ & $\mathbf{1} \backslash \mathbf{4}$ \\
\hline 1.016 and thinner & $\mathrm{D}$ & $\mathrm{D}$ & $\mathrm{D}$ & $\mathrm{D}$ & $\mathrm{D}$ & $\mathrm{D}$ \\
1.219 & $\mathrm{C}$ & $\mathrm{D}$ & $\mathrm{D}$ & $\mathrm{D}$ & $\mathrm{D}$ & $\mathrm{D}$ \\
1.626 and 1.422 & $\mathrm{C}$ & $\mathrm{C}$ & $\mathrm{D}$ & $\mathrm{D}$ & $\mathrm{D}$ & $\mathrm{D}$ \\
2.032 and 1.829 & $\mathrm{C}$ & $\mathrm{C}$ & $\mathrm{C}$ & $\mathrm{D}$ & $\mathrm{D}$ & $\mathrm{D}$ \\
2.337 & $\mathrm{C}$ & $\mathrm{C}$ & $\mathrm{C}$ & $\mathrm{C}$ & $\mathrm{D}$ & $\mathrm{D}$ \\
2.642 & $\mathrm{C}$ & $\mathrm{C}$ & $\mathrm{C}$ & $\mathrm{C}$ & $\mathrm{C}$ & $\mathrm{D}$ \\
2.946 and thicker & $\mathrm{C}$ & $\mathrm{C}$ & $\mathrm{C}$ & $\mathrm{C}$ & $\mathrm{C}$ & $\mathrm{C}$ \\
\hline
\end{tabular}

Note: $\mathrm{C}=$ cut countersunk; $\mathrm{D}=$ dimple.

Since the advent of all-metal vehicles, fastener installation has been one of the most important factors in structure fabrication. There are two factors which make fasteners extremely important. In the first place, all modern air vehicles are of stressed-skin construction. That is, the ribs, spars, formers, and longerons do not contribute all of the strength of the wings and fuselage. Instead, the skin contributes a large portion of that strength, and the skin and internal construction together form an integral, complete structure in which every particle of metal is under stress. Since fasteners are the primary means of attaching all the separate parts together, it is extremely important that each fastener be capable of taking its full share of the load $[7,8]$.

In the second place, since fasteners are used so extensively in structure construction, they contribute a large proportion of the cost of manufacture. The cost of the fasteners alone is small, but the manpower and machines to install them are large. From these two factors, (1) the importance of the strength of each fastener and (2) the high cost of fastener installation, it may readily be understood that every effort must be made to produce highly efficient joints and to use the best method for producing those joints. To obtain high strengths in all joints, together with the aerodynamic skin smoothness that is necessary, the coin dimple joint has become standard on modern air vehicles. This research paper is intended to explain how and why ram coin dimpling can produce better air-frames structurally and aerodynamically, and how dimpling can be accomplished efficiently.

In this paper we will highlight the main reasons to choose ram coin dimpling instead of countersinking in specific cases. After choosing dimpling, we should see with experiment which type of dimpling suits best some particular use.

Our experiments were carried out using the ZT2021D BLIND PULL GUN PORTABLE DIMPLER (Figure 2) when associated with ZT2409G THERMO DIMPLER CONTROL PANEL (Figure 1).

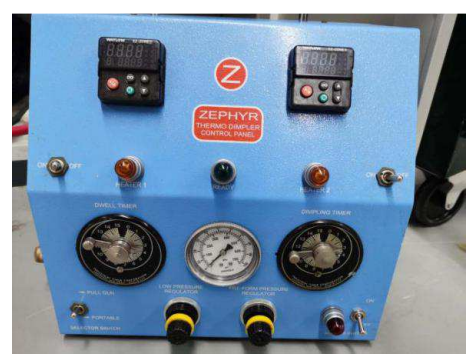

Figure 1. ZT2409G Thermo Dimpler Control Panel.

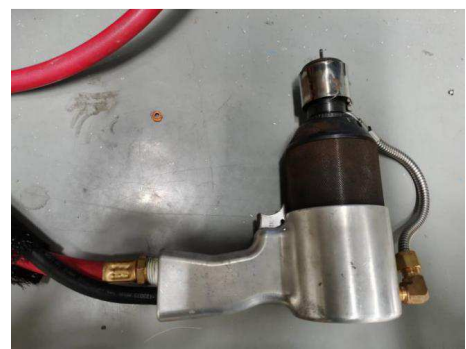

Figure 2. ZT2021D Blind Pull Gun Portable Dimpler.

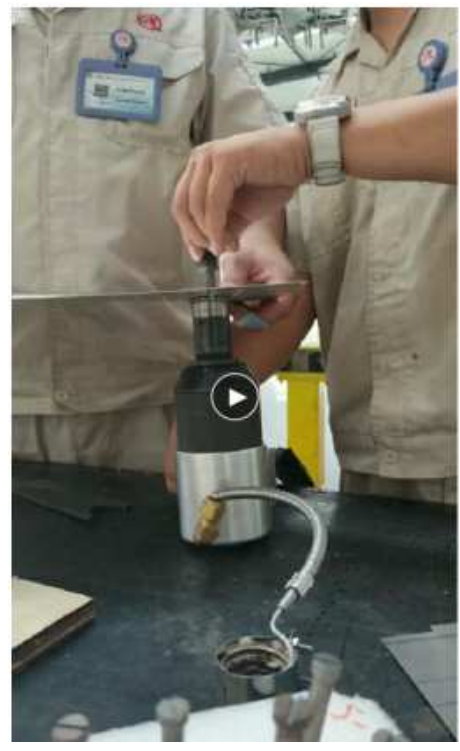

Figure 3. ZT2021D Blind Pull Gun Portable Dimpler being used.

\section{Why Ram Coin Dimpling Is Essential}

As the aircraft industry has progressed to higher speeds, it became important to eliminate the drag caused by the protruding heads of fasteners which was not a big concern in the early days when the wings were of large area and the speeds were low. Countersinking the skin panels to take a conical head fastener was a solution, but in thin skin panels, the removal of metal results in a joint with insufficient strength [9]; Dimpling is found to be the answer.

Dimpling removes no metal and, because of the "nesting" effect, gives a stronger joint than a non-flush construction. For all practical purposes, the head of the fastener was flush with the surface of the skin, and drag had been reduced. However, the dimples were of the radius type and not perfect. Around each head, there existed a depression, due to the fact that the 
surface of the skin had been gradually drawn down along a curved section to the angle of the fastener head. Tolerances were allowed, which made it possible for the heads to project slightly.

The use of the ram coin dimpling process has improved these conditions considerably. Theoretically a coin dimple is exactly the same size and shape as the conical head of the flush fastener so that it will seat perfectly flush, with no depression around the edge of the head. It is very important that the rivet hole be of the correct size and shape and free from burrs. If the hole is too small, the protective coating is scratched from the rivet when the rivet is driven through the hole. If the hole is too large, the rivet does not fill the hole completely. When it is bucked, the joint does not develop its full strength, and structural failure may occur at that spot $[10,11]$.

With the present high speeds of jet air vehicles, even very minute variations in skin contour become extremely important. Consequently, all methods and processes which affect skin smoothness must be considered for highest quality workmanship.

\section{Coin Dimpling Problems with Various Metals}

The making of a dimple includes 3 forces involved which tend to crack the material.

First, in brittle materials and in thin gages where there is insufficient stock to accommodate the stretch around the hole, radial crack-outs may occur. In the second place, the downward bending over the die cavity sets up tension stresses in the upper portion of the material, creating another type of stretch, which may cause a crack running circumferentially around the dimple. The third force is a heavy shear load inside the sheet just below the break of the dimple, most serious in the heavier gages of 7075-T6 alclad because of the greater amount of pressure exerted. As these shear cracks are internal, they cannot be detected except by sectioning the dimple for microscopic study.

The particular type of cracking conditions will vary according to the gage and type of material being dimpled, so the operator must always be on the alert for any changes of variations which may be encountered. For example, 2024-T3 aluminum alloy can be satisfactorily dimpled either hot or cold, but may crack in the vicinity of the dimple after cold dimpling because of hard spots in the metal. Hot dimpling prevents such cracking [12, 13].

7075-T6 aluminum alloys are always hot dimpled. Magnesium alloys also must be hot dimpled because, like 7075-T6, they have low formability qualities. Titanium is another metal that must be hot dimpled because it is tough and resists forming. The same temperature and dwell time used to hot dimple 7075-T6 is used for titanium.

\section{Sheet Materials}

The type of sheet material being used in an assembly is very important from the dimpling stand-point. The demand for harder and stronger materials in the development of air vehicles has resulted in several alloys which are now in use, and each presents a different dimpling problem [14].

The application of heat when dimpling the more brittle materials is advantageous for the reduction of cracking, and also from the stand-point of dimple formation.

Heat is applied to the material by the dies, which are maintained at a specified temperature by the attached electrical strap heaters. The heat is thus momentary and localized, so that hot dimpling is no more difficult than cold dimpling, except in a very few cases where space limitations may cause interference with the heaters.

However, because of the heat requirements and the additional controls necessary, hot dimpling requires more carefulness.

In our case we used;

1. Specimen $2024-T 30.6 \mathrm{~mm}$ thick, size $160 \times 180$, quantity 2 pieces.

2. Specimen 2024-T42 $0.6 \mathrm{~mm}$ thick, size $160 \times 180$, quantity 1 piece.

3. Specimen $2024-T 32 \mathrm{~mm}$ thick, size $160 \times 180$, quantity 1 piece.

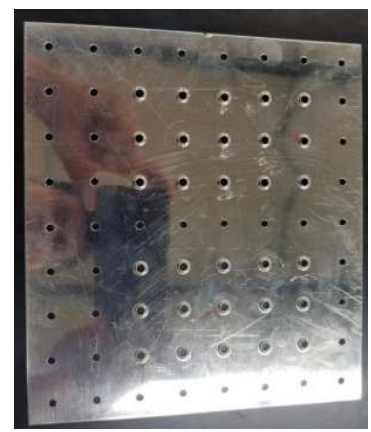

Figure 4. 0.6mm thick 2024-T3 test piece.

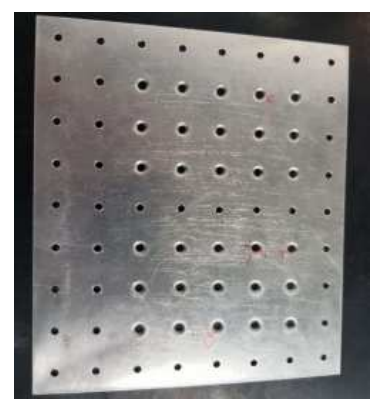

Figure 5. 0.6mm thick 2024-T42 test piece.

\section{Experiments}

\subsection{Coin Dimpling Test Tools and Set-up}

\section{A. Test tool}

(1) ZT2021 hand-held hot dimpling machine (producing a maximum pressure of $12000 \mathrm{lb}$ and an air source pressure of 90psi);

(2) ZT2409G Hot dimpling machine temperature controller (input voltage $110 \mathrm{~V}$ alternating current, can provide the maximum temperature $900^{\circ} \mathrm{F}$ ), 
during the dimpling process to control the temperature;

(3) Drilling tools and cutters: HSS straight shank high-speed steel bit, 0.098 (40\#) drill, 0.1285 (30\#) drill, 2 pieces;

(4) HSS high-speed steel spot drill, $100^{\circ} 4$ rivet spot drill, 2 pieces;

(5) Test bench: 1;

(6) Other tools: marker pen, rubber, ruler, cleaning solvent acetone (GB/T686), etc.;

B. Measuring and inspection tools

(1) Measuring tool for aperture inspection: vernier caliper (model: SYTQM-G-211;

(2) Measuring tools for checking the size of countersunk pit: 1 piece of pit diameter gauge,

(3) Flatness measuring instrument: flatness gauge (model: SYTQM-A-35), 1 piece;

(4) An infrared temperature detection device with a maximum range of $500^{\circ} \mathrm{C}$, including 1 timer for each device;

(5) Fluorescent inspection tools: Black light: SYTQM-E-13\SYTQM-E-14/ SYTQM-E-15;

Digital photometer: SYTQM-E-09; Fluorescence intensity meter: SYTQM-E-11; A set of above fluorescence inspection tools.

\section{Hot dimpling Test process}

During This whole process we have to make sure we're thoroughly cautious about Hole Drilling and deburring:

1. Ensure the drill bit is the correct size and shape.
2. Place the drill in the center-punched mark. When using a power drill, rotate the bit a few turns before starting the motor.

3. While drilling, always hold the drill at a $90^{\circ}$ angle to the work or the curvature of the material.

4. Avoid excessive pressure, let the drill bit do the cutting, and never push the drill bit through stock.

5. Remove all burrs with a metal countersink.

6. Clean away all drill chips.

When holes are drilled through sheet.

metal, small burrs are formed around the edge of the hole. This is especially true when using a hand drill because the drill speed is slow and there is a tendency to apply more pressure per drill revolution. For better results we remove all burrs with a burr remover or larger size drill bit before riveting.

Once the rivet is installed, there should be no evidence of rotation of rivets or looseness of riveted parts. After the trimming operation, we examine for tightness. We Apply a force of 10 pounds to the trimmed stem. A tight stem is one indication of an acceptable rivet installation. Any degree of looseness indicates an oversize hole and requires replacement of the rivet with an oversize shank diameter rivet. A rivet installation is assumed satisfactory when the rivet head is seated snugly against the item to be retained $(0.005$-inch feeler gauge should not go under rivet head for more than one-half the circumference) and the stem is proved tight. This would mark a successful dimpling.

Table 2. Sheet material properties and processing method used.

\begin{tabular}{lllll}
\hline Aluminum plate specification & $\mathbf{0 . 6 m m 2 0 2 4 - T 3}$ & $\mathbf{0 . 6 m m 2 0 2 4 - T 3}$ & 0.6mm2024-T42 & 2mm2024-T3 \\
\hline number & $\# 1$ & $\# 2$ & $\# 3$ & dimpling \\
$\begin{array}{l}\text { Processing method } \\
\text { riveting }\end{array}$ & dimpling & dimpling & & \\
\hline
\end{tabular}

The test steps of hot dimpling are as following:

(1) At the beginning of the test line, we make sure all the source holes are $\Phi 2.4 \mathrm{~mm}$.

(2) the test piece preparation: respectively $1 \# \sim 4 \#$ test pieces, drill 30 holes of $\Phi 2.4 \mathrm{~mm}$, and expand them to $\Phi$ $3.2 \mathrm{~mm}$ hole, remove burrs.

(3) Hot dimpling machine settings: plug together the hand-held hot dimpling machine (Figure 2) to the thermo dimpler control panel (Figure 1), install $\Phi$ $3.2 \mathrm{~mm}$ die, switch the temperature controller on, hand-held hot dimpling machine air pressure is adjusted to $90 \mathrm{psi}$, set the temperature to $343^{\circ} \mathrm{C}\left(650^{\circ} \mathrm{F}\right)$.

(4) After the pressure socket device stabilizes at $343^{\circ} \mathrm{C}$, the temperature value of the temperature control device is recorded, and then pressure test is carried out.

(5) After the completion of the pressure test, check the pressure test forming according to item 9 of the test outline GA20-TM-001-T0-01. According to the actual forming situation, we use gaskets to adjust the portable dimpler set-up gap until the dimpling forming situation is good and stable.

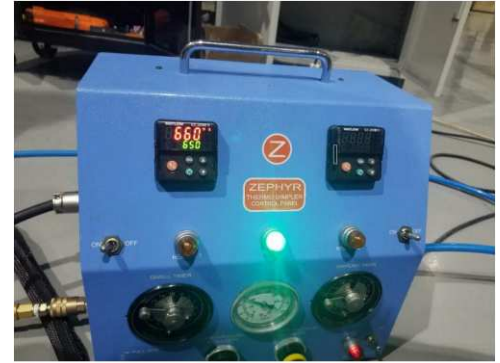

Figure 6. The temperature controller sets the dimpling temperature at $343^{\circ} \mathrm{C}$ $\left(650^{\circ} \mathrm{F}\right)$.

(6) After the pressure test condition is good and stable, the no. $1 \sim$ no. 3 test pieces are respectively carried out the pressure nest test. Insert the pressure socket into the corresponding position of the test plate, insert the guide end into the hole, and then pull the "trigger" device pressure socket. After the pressure socket is completed, release the "trigger" and we recorded the temperature and dwelling time in Table 3 results. 
Table 3. Experimental results for hot dimpling.

\begin{tabular}{lllllll}
\hline \multicolumn{2}{l}{ Experimental data of hot dimpling } & & & \\
\hline $\mathbf{n}^{\circ}$ & Sandwich material and thickness & Rivet Type & Diameter specifications & Temperature & Time & Forming conditions \\
\hline 1 & $1 \#(2024-\mathrm{T} 3,-0.6 \mathrm{~mm})$ & NAS9302B4-02\MS20426D4-3 & $3.20-3.29$ & $650^{\circ} \mathrm{F}$ & $3-4 \mathrm{~s}$ & No defects, no cracks \\
2 & $2 \#(2024-\mathrm{T} 3,-0.6 \mathrm{~mm})$ & NAS9302B4-02\MS20426D4-3 & $3.20-3.30$ & $650^{\circ} \mathrm{F}$ & $3-4 \mathrm{~s}$ & No defects, no cracks \\
3 & $3 \#(2024-\mathrm{T} 42,-0.6 \mathrm{~mm})$ & NAS9302B4-02\MS20426D4-3 & $3.20-3.30$ & $650^{\circ} \mathrm{F}$ & $3-4 \mathrm{~s}$ & No defects, no cracks \\
\hline
\end{tabular}

\section{(7) Inspection:}

a) According to item 9 of the test outline GA20-TM-001-T0-01, we check the dimple forming effect of no. $1 \sim$ no. 3 test pieces, visually inspect the appearance quality with visual and 4-10 magnifier, we use vernier caliper to check the aperture, and fill in the forming condition in Table 3.

b) Fluorescent inspection tool is used to conduct fluorescent inspection on the test plate, and the forming condition is filled in Table 3 .

(8) After testing and recording the hot dimpling method results, we go on with the riveting.

The steps of riveting are as following:

1) clamp the tested plates \# 1 and \# 3 together, and \# 2 and \# 4 together;

2) According to the specification of GA20-PS-062 Common Riveting, the holes on the $1 \# \& 3 \#$ combined test plate are divided into two groups of 15 holes each, one group of rivet MS20426D4-3 countersunk rivets, the other group of rivets NAS9302B4-02 countersunk rivets; Similarly, two sets of holes in the $2 \# \& 4 \#$ combined test plate, one set of rivet MS20426D4-4 countersunk rivets, the other set of rivets NAS9302B4-02 countersunk rivets.
3) Check rivet head evenness and rivet forming after rivet joint, and the results are recorded in Table 5. kyoung-yun kim [15] and colleagues demonstrated some riveting quality measures in their study.

\subsection{Coin Dimpling Results and Discussions}

To determine the quality of a dimple, it is necessary to make a close visual inspection. Several features must be checked. The rivet head should fit flush and there should be a sharp break from the surface into the dimple. The sharpness of the break is affected by dimpling pressure and metal thickness [16]. Selected dimples should be checked by inserting a fastener to make sure that the flushness requirements are met. In our case we used rivets and Table 4 shows details about the standard rivets.

Table 4. Drill sizes for standard rivets.

\begin{tabular}{lll}
\hline \multirow{2}{*}{ Rivet Diameter (in) } & Drill Size & \\
\cline { 2 - 3 } & Pilot & Final \\
\hline $3 / 32$ & $3 / 32(0.0937)$ & $\# 40(0.098)$ \\
$1 / 8$ & $1 / 8(0.125)$ & $\# 30(0.1285)$ \\
$5 / 32$ & $5 / 32(0.1562)$ & $\# 21(0.159)$ \\
$3 / 16$ & $3 / 16(1.1875)$ & $\# 11(0.191)$ \\
$1 / 4$ & $1 / 4(0.250)$ & $\mathrm{F}(0.257)$ \\
\hline
\end{tabular}

Table 5. Experimental results for riveting.

\begin{tabular}{|c|c|c|c|c|c|c|c|}
\hline \multicolumn{8}{|c|}{ Experimental data of riveting } \\
\hline $\mathbf{n}^{0}$ & $\begin{array}{l}\text { Sandwich material and thickness } \\
\text { (From head to tail) }\end{array}$ & Rivet Type & $\begin{array}{l}\text { Fitting } \\
\text { situation }\end{array}$ & Riveting & $\begin{array}{l}\text { Upset } \\
\text { head }\end{array}$ & Nail head & Flatness \\
\hline 1 & $\begin{array}{l}2024-\mathrm{T} 30.6 \mathrm{~mm} \text { and } 2024-\mathrm{T} 42 \\
0.6 \mathrm{~mm}\end{array}$ & NAS9302B4-02\MS20426D4-3 & $\begin{array}{l}\text { Hole and } \\
\text { socket fit }\end{array}$ & $\begin{array}{l}\text { up to } \\
\text { standard }\end{array}$ & $\begin{array}{l}\text { up to } \\
\text { standard }\end{array}$ & $\begin{array}{l}\text { No defects, } \\
\text { no cracks }\end{array}$ & $\begin{array}{l}\text { satisfies } 0-0.08 \mathrm{~mm} \\
\text { requirement }\end{array}$ \\
\hline 2 & 2024-T3 $0.6 \mathrm{~mm}$ and $2024-\mathrm{T} 32 \mathrm{~mm}$ & NAS9302B4-02\MS20426D4-4 & $\begin{array}{l}\text { Hole and } \\
\text { socket fit }\end{array}$ & $\begin{array}{l}\text { up to } \\
\text { standard }\end{array}$ & $\begin{array}{l}\text { up to } \\
\text { standard }\end{array}$ & $\begin{array}{l}\text { No defects, } \\
\text { no cracks }\end{array}$ & $\begin{array}{l}\text { satisfies } 0-0.08 \mathrm{~mm} \\
\text { requirement }\end{array}$ \\
\hline
\end{tabular}

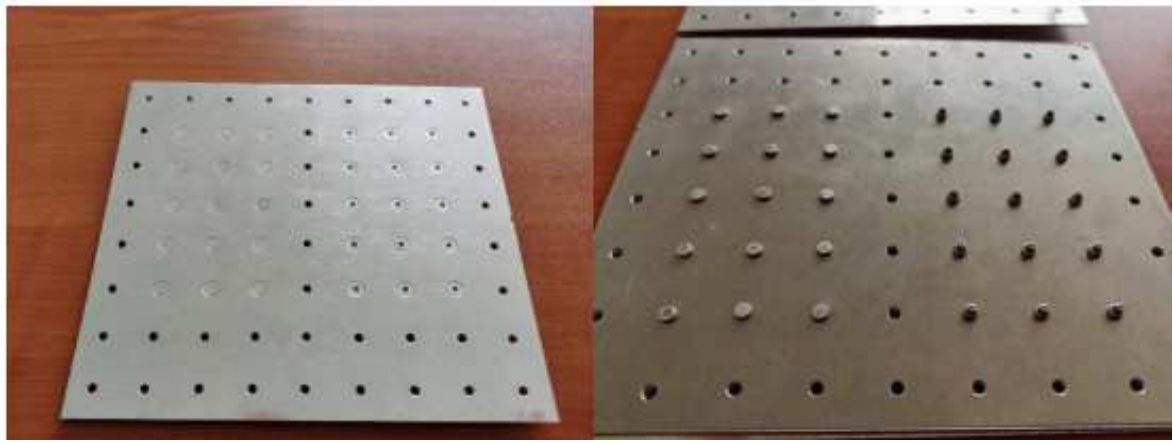

Figure 7. Rivet head and upset head after riveting of aluminum plate.

Cracked dimples are caused by poor dies, rough holes, or improper heating.

Two types of cracks may form during dimpling:

1) Radial cracks - start at the edge and spread outward as the metal within the dimple stretches. They are most common in 2024-T3. A rough hole or a dimple that is too deep causes such cracks. A small tolerance is usually allowed for radial cracks. 
2) Circumferential cracks - downward bending into the draw die causes tension stresses in the upper portion of the metal. Under some conditions, a crack may be created that runs around the edge of the dimple. Such cracks do not always show since they may be underneath the cladding. When found, they are cause for rejection. These cracks are most common in hot-dimpled 7075 T6 aluminum alloy material. The usual cause is insufficient dimpling heat.

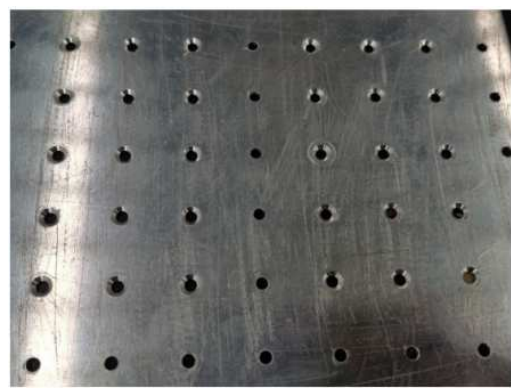

Figure 8. Successful dimple.

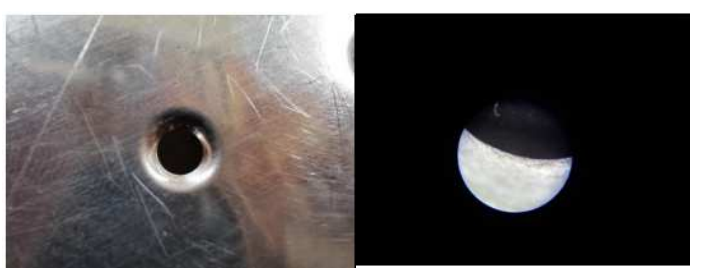

Figure 9. 60x magnifier of the dimple.

1. Drilling hole position diameter has to be chosen according to the needed dimple diameter, deburring before dimpling have to be done with caution and accuracy otherwise the dimple will have a much bigger diameter than the intended rivet and it will hang loose.

2. The holes that were deburred by hand ended up slightly smaller, and was too small for the rivet to fit. The Burr-away removed some material and enlarged the hole If you get too aggressive deburring, your holes might be too large. If not deburred enough, then you might have to upsize the hole.

\subsection{Tensile Test Results and Discussions}

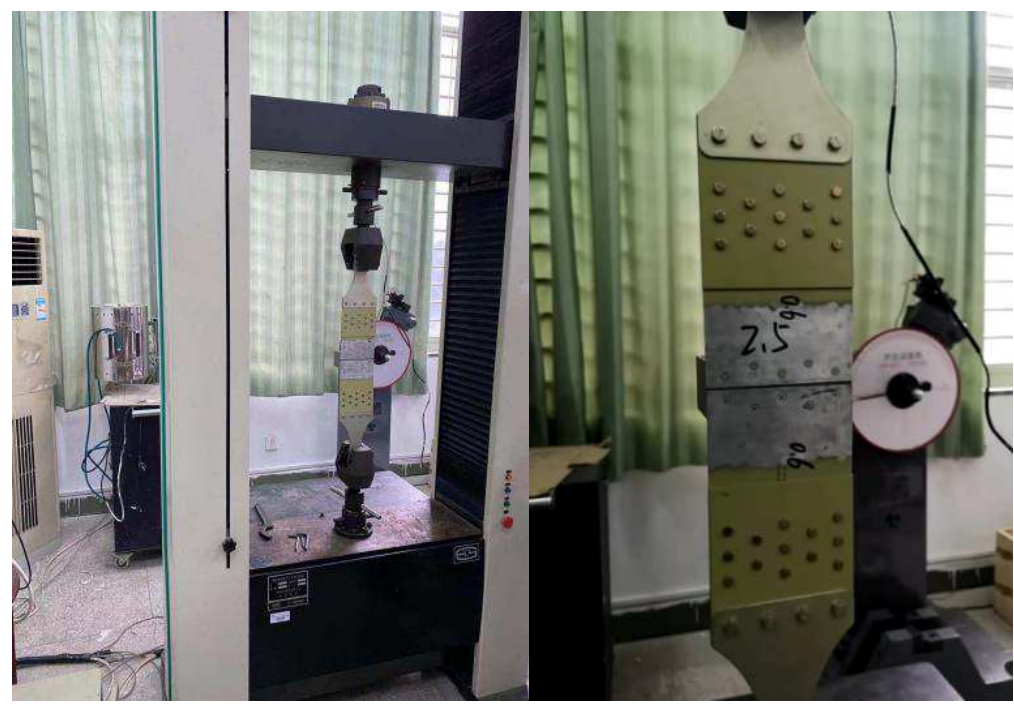

Figure 10. Specimen installed on tension machine.

Table 6. Results and discussions.

\begin{tabular}{|c|c|c|c|c|c|c|}
\hline $\begin{array}{l}\text { Specimen } \\
\text { ID }\end{array}$ & $\begin{array}{l}\text { Sheet } \\
\text { material }\end{array}$ & Configuration & $\begin{array}{l}\text { Failure } \\
\text { value KN }\end{array}$ & $\begin{array}{l}\text { Fastener } \\
\text { number }\end{array}$ & $\begin{array}{l}\text { Allowable } \\
\text { value } \mathbf{N}\end{array}$ & Failure mode \\
\hline 1.1 & \multirow{5}{*}{$\begin{array}{l}\text { countersunk } \\
\text { for } 0.8 \mathrm{~mm} \text {, } \\
\text { skin dimpling } \\
\text { on } 0.6 \mathrm{~mm} \\
\text { doubler }\end{array}$} & blind rivet both sides & 10.71 & 5 & 2142 & $\begin{array}{l}\text { fastener shearing off (then rivet head offset } \\
\text { along the slope and snap the inner rod) }\end{array}$ \\
\hline 1.2 & & \multirow{4}{*}{$\begin{array}{l}\text { solid rivet both sides } \\
\text { blind \& solid each side } \\
\text { blind both sides, doubler no } \\
\text { fastener } \\
\text { solid both sides, doubler no } \\
\text { fastener }\end{array}$} & 11.18 & 5 & 2236 & $\begin{array}{l}\text { fastener shearing failure together with a big } \\
\text { noise of snap and flat fracture surface }\end{array}$ \\
\hline 1.3 & & & 10.34 & 5 & 2068 & Same as 1.1 \\
\hline 1.4 & & & 6.54 & 5 & 1308 & $\begin{array}{l}\text { fastener shearing off (then snap inner), 2nd } \\
\text { moment is obvious }\end{array}$ \\
\hline 1.5 & & & 9.19 & 5 & 1838 & $\begin{array}{l}\text { Skin bearing, edge shear in tearing, 2nd } \\
\text { moment }\end{array}$ \\
\hline 2.1 & \multirow{4}{*}{$\begin{array}{l}\text { dimpling } \\
0.8 \mathrm{~mm} / \\
0.6 \mathrm{~mm} \text { skin }\end{array}$} & solid rivet, $0.8 \mathrm{~mm}$ skin, both sides & 10.44 & 5 & 2088 & skin bearing, then skin edge tearing \\
\hline 2.2 & & blind rivet, $0.8 \mathrm{~mm}$ skin, both sides & 9.26 & 5 & 1852 & skin bearing \\
\hline 2.3 & & solid rivet, $0.6 \mathrm{~mm}$ skin, both sides & 8.44 & 5 & 1688 & skin bearing \\
\hline 2.4 & & blind rivet, $0.6 \mathrm{~mm}$ skin, both sides & 7.33 & 5 & 1466 & skin bearing \\
\hline
\end{tabular}




\begin{tabular}{|c|c|c|c|c|c|c|}
\hline $\begin{array}{l}\text { Specimen } \\
\text { ID }\end{array}$ & $\begin{array}{l}\text { Sheet } \\
\text { material }\end{array}$ & Configuration & $\begin{array}{l}\text { Failure } \\
\text { value KN }\end{array}$ & $\begin{array}{l}\text { Fastener } \\
\text { number }\end{array}$ & $\begin{array}{l}\text { Allowable } \\
\text { value } \mathbf{N}\end{array}$ & Failure mode \\
\hline 2.5 & & $\begin{array}{l}\text { blind \& solid each side, } 0.6 \mathrm{~mm} \\
\text { skin both sides }\end{array}$ & 7.58 & 5 & 1516 & skin bearing \\
\hline \multirow{3}{*}{3.1} & \multirow{6}{*}{$\begin{array}{l}0.3 \mathrm{~mm} \text { skin } \\
\& \text { blind/solid }\end{array}$} & & 0.86 & 1 & 860 & Bearing (no flange snap) \\
\hline & & $0.3 \mathrm{~mm}$ skin, blind, new tooling & 0.99 & 1 & 990 & Bearing (no flange snap) \\
\hline & & & 0.93 & 1 & 930 & Bearing (no flange snap) \\
\hline \multirow{3}{*}{3.2} & & & 0.86 & 1 & 860 & Bearing (no flange snap) \\
\hline & & $0.3 \mathrm{~mm}$ skin, solid, new tooling & 0.87 & 1 & 870 & Flange edge snap and root bearing \\
\hline & & & 0.87 & 1 & 870 & Flange edge snap then skin tear \\
\hline conclusion & \multicolumn{6}{|c|}{$\begin{array}{l}\text { For design and stress: } \\
\text { 1. Take care of } 2 \text { nd moment, which will reduce fastener shearing and skin bearing allowable. Shall use single shearing allowable value from test } \\
\text { for lap joint analysis. If add a shim, which must do test or use doubler instead, and avoid use blind rivet. } \\
\text { 2. Doubler can reduce } 2 \text { nd moment and add load path, which will lead the shearing failure earlier than bearing. This will lead to a lack of the load } \\
\text { redistribution process based on bearing yield, so it's very important to make sure there's no shearing failure on each fastener. for end fastener, use } \\
\text { steel fastener; } \\
\text { 3. Blind rivet has lower bearing than solid. For bearing, reduce factor } 0.8 \text { can be enough. } \\
\text { 4. Blind rivet shearing allowable is not absolutely higher than solid. In this test, all lower. } \\
\text { 1. doubler can reduce } 2 \text { nd moment, it's obvious by watching; } \\
\text { 2. shim (doubler without rivets) increase the } 2 \text { nd moment, which reduce the bearing allowable, and blind rivet be affected much more (1.4 VS } \\
\text { 2.2; } 1.5 \text { VS } 2.1) \text {; } \\
\text { 3. } 2 \text { nd moment reduce fastener shearing allowable, especially blind, even can make shearing lower than bearing.(1.4 VS } 2.2) \\
\text { 4. doubler reduce the work load on the skin hole due to multiple load path, so that shearing on the pin can happen earlier than skin bearing (1.1 } \\
\text { VS } 2.2 ; 1.2 \text { VS } 2.1 \text { ) } \\
\text { 5. Blind shearing is not higher than solid ( } 1.1 \text { VS } 1.2) ; \\
\text { 6. Blind bearing is lower than solid, factor }>1.15(2.1 \text { vs } 2.2 ; 2.3 \text { vs } 2.4 / 2.5) \text {; }\end{array}$} \\
\hline
\end{tabular}

*Notes:

Blind: Blind rivet, NAS9302B-4-02

Solid: Solid rivet, MS20426D4

Old tooling: The diameter $3.2 \mathrm{~mm}$ dimpling tooling used, which lead to $3.6-3.7 \mathrm{~mm}$ holes; cold dimpling.

New tooling: The diameter $2.7 \mathrm{~mm}$ dimpling tooling used, which lead to $3.1-3.2 \mathrm{~mm}$ holes; cold dimpling.

Hot dimpling: used on $0.3 \mathrm{~mm}$ skin panel.

\section{Conclusion}

1. D3.2mm solid and blind rivet simple lap joint with $0.8 \mathrm{~mm}$ skin will fail due to bearing, not shearing;

2. Doubler can reduce bearing's work load and make shearing happen first, the shearing fail happen suddenly without load redistribution due to bearing yield;

3. For counter sunk shearing and bearing, solid rivets' test value match theoretical one very well, but blind rivet less. And solid ones are less affected by 2 nd bending moment than blind one;

4. For design principle: Blind rivet is a little bit better than solid rivet for static, but both acceptable. Shearing failure is impossible, the left failure mode is flange snap/tear and bearing, bearing is better than flange snap/tear. Solid make flange snap easier, but blind not, only bearing.

5. Only the condition of dimpling with $0.3 \mathrm{~mm}$ skin inside, the blind rivet reduce dimpling flange snap risk and have higher allowable;

6. Tooling size is important for dimpling process performance. D2.7mm tooling is suitable for D $3.2 \mathrm{~mm}$ holes. For manufacturing process: Controlling dimpling tool diameter is the most important, new tooling $\mathrm{D} 2.7 \mathrm{~mm}$ for D3.2mm hole on $0.3 \mathrm{~mm}$ skin is acceptable. Better avoid bigger tooling;
7. For stress analysis: The bearing allowable value for dimpling/solid rivet can be calculated by Formula. Fbru $=D^{*} t * \sigma b r u$, without any reducing coefficient. (where Fbru is the ultimate bearing load; D is the diameter; $t$ is the thickness and obru is the coefficient of the ultimate bearing load.) blind is a little better, without any reducing coefficient. That is why saying dimpling bearing is better than countersunk.

8. Hot dimpling though requiring a lot more attention proves to be more efficient on thick or brittle sheet materials, where cold dimpling would produce radial cracks.

All in all, the ram coin dimpling processes are of a huge value in achieving high strength structural connections and smooth aerodynamic surfaces. It still requires more researches in order to get the best of these methods though.

\section{Acknowledgements}

This research has been done on a full approval of GUANYI AVIATION and TIANQIMO AIRCRAFT PARTS MANUFACTURING COMPANY.

There is no financial support or grants of any kind received for this research. I would like to thank Mr. LIANG FEI, ZEN HUI and REN ZEN LI for their technical assistance and advice. Much appreciation to Prof. WU JIN WU, my supervisor, and the personnel at NANCHANG HANGKONG UNIVERSITY aircraft manufacturing 
school, who helped with the tensile and shear tests. The information provided by ZEPHYR MANUFACTURING CO., INC. Of ZEPHYR TOOL GROUP was also of a huge help.

\section{References}

[1] C. Rans, P. V. Straznicky (2004); "Avoiding knife-edge countersinks in Glare through dimpling". Department of Mechanical and aerospace engineering, Carleton University, Ottawa, Canada.

[2] Müller, R. P. G. (1995), “An experimental and analytical investigation on the fatigue behaviour of fuselage riveted lap joints: the significance of the rivet squeeze force and a comparison of 2024-T3 and Glare 3." PhD. dissertation, Delft University of Technology, Delft, The Netherlands.

[3] Urban MR (2003) Analysis of the fatigue life of riveted sheet metal helicopter airframe joints. Int J Fatigue.

[4] Sohel Rana M, Makabe C, Fujiwara G (2009) The effect of hole shape on the extent of fatigue life improvement by cold expansions. Eng Fail Anal.

[5] Young, J. B., Lee, K. K. (1993), "Stress concentration factors in countersunk holes," Aeronautical Journal, 97, (968), 267-276.

[6] Bombardier Aerospace, SD 3-60 Structural repair manual.

[7] George Nadim Melhem. (2019); Aerospace Fasteners: Use in structural Applications. Encyclopedia of aluminum and Its Alloys (pp. 30-45).
[8] G. Nadim Melhem, P. Munroe, C. Sorrell. (2019) Field Trials of Aerospace Fasteners in Mechanical and Structural Applications.

[9] Park CY, Grandt Jr AF, Suh JJ (2006) Stress intensity factors for surface cracks at countersunk holes. Eng Fract Mech.

[10] V. B. Nguyen, C. J. Wang, D. J. Mynors et al., Dimpling process in cold roll metal forming by finite element modeling and experimental validation. J. Manuf. Process.

[11] V. B. Nguyen, C. J. Wang, D. J. Mynors, M. A. English, M. A. Castellucci, Compression tests of cold-formed plain and dimpled steel columns. J Construct Steel Res.

[12] Chishti, M.; Wang C.; Thomson, R.; Orifici, A. Experimental investigation of damage progression and strength of countersunk composite joints. Compos. Struct. 2012, ^\$.94 (3), 865-873.

[13] Liu Y S, He X D, Shao X J, et al. Analytical and experimental investigation of fatigue and fracture behaviors for anti-double dog-bone riveted joints. Engineering Failure Analysis 2010; 17 (6): 1447-1456.

[14] Ray Ms, Matthew IR, Frame JW (1998) Metallic fragments on the surface of miniplates and screws before insertion. British J Oral Maxill Surg.

[15] Kyoung-Yun Kim, Jaemun Sim, Noor-E Jannat, Fahim Ahmed, Sattar Ameri (2019) Challenges in riveting quality prediction: a literature survey; Department of Industrial and Systems Engineering, Wayne State University, Detroit, MI 48202, USA.

[16] Dr. ir. R. C. (René) Alderliesten, (2018) Introduction to Aerospace Structures and Materials. 